Digilec 8 (2021), pp. 36-52

Fecha de recepción: 13/08/2021

Fecha de aceptación: 28/09/2021

DOI: https://doi.org/10.17979/digilec.2021.8.0.8658

(ब)

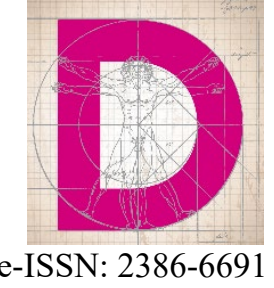

\title{
A RECOMPILACIÓN DE MÚSICA E BAILE DE TRADICIÓN ORAL EN GALICIA: AS RECOLLIDAS
}

\author{
THE COMPILATION OF MUSIC AND DANCE OF ORAL TRADITION \\ IN GALICIA: THE "RECOLLIDAS"
}

\author{
Carme LÓPEZ FERNÁNDEZ* \\ Universidade da Coruña \\ Orcid: https://orcid.org/0000-0002-9661-4511
}

\section{Resumo}

Este artigo versa sobre un proceso de recompilación de músicas e bailes de tradición oral que se deu en Galicia, especialmente durante a década dos 90 e que se popularizou baixo o nome de recollidas. A súa relevancia ven dada polo gran número de persoas implicadas e a influencia que tivo na conformación actual da música e baile tradicional galegos. Ademais, o escaso tratamento e conexión das recollidas co campo científico-académico supón un baleiro moi propicio sobre o que investigar.

Relacionado coa escaseza de publicacións, abordamos esta investigación coa entrevista como método fundamental para a achega de información, traballando para isto con diferentes persoas do sector da música e baile tradicional que tiveran participado en recollidas durante a década dos 90 .

Neste texto recollemos, a través das vivencias destes profesionais, un relato no que se define, marcan os obxectivos, describe o proceso máis resultados deste fenómeno de recompilación. Ademais, tamén abordamos algunhas das influencias que estes traballos de investigación tiveron na propia tradición. Por último, tamén valoramos a importancia destas compilacións e a gran posibilidade para o futuro, tendo en conta a existencia dunha gran cantidade de material aínda sen catalogar e analizar.

Palabras chave: traballo de campo; música tradicional; baile tradicional; tradición oral; recollidas

\footnotetext{
Abstract

This article is about a process of compiling music and dances of oral tradition that took place in Galicia, especially during the 1990s and that became popular under the name of "recollidas". Its relevance lies on the large number of people involved and on its influence
}

* carme.lopez.fernandez@udc.es 
on the current shape of traditional Galician music and dance. In addition, the poor treatment and connection of the collections with the scientific-academic field constitutes a conducive vacuum on which to investigate. Due to the scarcity of publications, we approached this research with the interview as the fundamental method for providing information, collaborating with people from the traditional music and dance sector who had participated in "recollidas" during the 1990s.

In this study we conduct, through the experiences of these professionals, a project in which the phenomenon of compilation is defined, its objectives are marked, and the process and the results are also delineated. In addition, we also address some of the influences that these research works have had on the tradition itself. Lastly, we also assess the importance of these compilations and the great possibility that they offer for the future, given the existence of a large amount of material still uncatalogued and not analysed.

Key Words: field work; traditional music; traditional dance; oral tradition; "recollidas"

Agradecementos: O meu máis sincero agradecemento a todas as persoas que participaron como informantes nas entrevistas realizadas. Tanto as súas vivencias máis persoais como aquelas reflexións máis enfocadas ao ámbito profesional fixeron posible a redacción deste artigo. 


\section{INTRODUCIÓN}

Neste artigo exponse un fenómeno xurdido en Galicia a partires dos anos 80 vinculado coa tradición e a súa preservación, especialmente enfocado cara a música e o baile de tradición oral, e coñecido baixo o nome de "recollidas". Estas recollidas vincúlanse co proceso de investigación etnomusicolóxica a pesares de que o desenvolvemento en Galicia se afastou, especialmente nos seus comezos e puntos álxidos, dos ámbitos científico ou académico.

Este distanciamento provocou que, a pesares de ser un fenómeno de significativa importancia para o eido da música e baile de tradición oral e para a súa expansión e repercusión na actualidade, non existan apenas publicacións sobre o mesmo. Este motivo foi fundamental para a proposta deste artigo, considerando unha necesidade imperiosa a existencia de referencias dende a academia a este proceso tan recoñecido dende outros ámbitos.

\section{MARCO TEÓRICO}

Debido ao escaso sustento teórico-académico arredor do sector da música tradicional galega, consideramos necesario establecer un primeiro apartado no que definir e sinalar uns conceptos básicos en relación ao noso obxecto de estudo e que plasmaremos tanto no apartado de conceptos chave como no de traballo de campo e recollidas, seguido dunha sección de revisión bibliográfica na que sinalaremos os que poden considerarse como antecedentes das recollidas.

\subsection{Conceptos chave}

Neste apartado definense unha serie de termos moi presentes nos estudos e na realidade tanto da música como do baile vinculados coa tradición, e que se mesturan e confunden abundantemente en estudos, traballos e eventos. Tomaremos como referencia o termo música, pero consideramos que os adxectivos que o acompañan relegarían o mesmo significado á palabra baile.

Comezaremos coa definición de música de tradición oral sinalando que a principal característica é a súa difusión mediante transmisión oral, é dicir, sen a intervención de apoios físicos ou audiovisuais como poderían ser partituras ou gravacións, por exemplo. Esta condición explica outra das súas calidades definitorias, a permanente variación debido a diferentes intérpretes, situacións ou interpretacións. Ademais, estas músicas presentan un vínculo indisoluble cunha sociedade ou cultura enmarcadas nun punto xeográfico concreto (Randel, 1997; Latham, 2009).

O termo música folklórica é empregado frecuentemente para nomear as músicas definidas no vocábulo anterior, é dicir, podería utilizarse como sinónimo de música de tradición oral (Randel, 1997). A pesares disto, temos que ter en conta que esta palabra 
parte doutro termo, o de folklore, ou saber do pobo, o cal foi considerado como o obxecto de estudo do folklorismo, a ciencia preocupada polo coñecemento das clases baixas e rurais que se desenvolveu en pleno Romanticismo por boa parte de Europa (Latham, 2009). Este contexto fai que, polo menos en certos espazos, non se considere adecuado falar de música folklórica ao estar impregnado este termo das consideracións da propia ciencia folklorista, marcada por múltiples nesgos como poden ser a busca dunha suposta autenticidade ou a variación da propia música a través de diversos procesos como a simplificación ou potenciación de signos distintivos (Martí, 1999).

Por último, o adxectivo máis estendido na actualidade para facer referencia a esta música que se desenvolveu no pasado mediante transmisión oral é o de tradicional, podendo atopalo tanto en múltiples publicacións: Martí (1998), Manzano (1995), Nettl (1985), Groba (1998), López Cobas (2013), etc.; como no propio sector de música e baile galegos, relacionados con escolas e espectáculos.

Sen embargo, a pesares do seu estendido uso, non existe consenso sobre a súa definición, motivo polo cal nos escollemos a que segue, entendendo que é unha proposta achegada á propia utilización que ten este termo:

Toda aquella música de tradición oral que hoy en día se transmite de forma diferente (se ha producido una ruptura en la transmisión oral) y se usa con objetivos distintos con los que se relacionaba antiguamente. Es decir, se trata de la música de tradición oral adaptada al contexto actual, marcado por la comunicación, la globalización y su introducción en el mercado como un bien más (López Fernández, en prensa).

\subsection{Traballo de campo e recollidas}

Despois de definir o que se presenta como o obxecto de estudo do proceso que describimos neste artigo, trataremos de enfocar o método e modo no que se produce o achegamento a esta información.

Atendendo ao marco científico-académico, o elemento máis próximo ao fenómeno das recollidas é o coñecido dentro da etnomusicoloxía como traballo de campo. O traballo de campo é, segundo Myres (en Cámara de Landa, 2016: 321) "una investigación programada por una o varias personas sobre un objeto predeterminado, con metodología no improvisada y mediante el uso de técnicas particulares".

Seguindo a Cámara de Landa (2016) este traballo de campo consistiría na visita por parte de investigadores ou investigadoras a un núcleo social concreto co obxectivo de coñecer certa información a través da observación e/ou contacto coas persoas partícipes do fenómeno a estudar. Non se trata dunha metodoloxía única, senón que é planificada e estruturada segundo os criterios do ou da investigadora e do caso particular. Aínda así, poderíamos falar dunha estrutura base na que sempre aparecerá unha formulación e preparación, o propio proceso no campo caracterizado especialmente pola documentación e gravación; máis unha fase final de análise e valoración de resultados.

As recollidas realizadas en Galicia a partires dos 70 e 80 , e con especial forza durante os 90, poderían definirse como a realización de traballo de campo por persoas 
non especializadas e que tiñan como obxectivo principal compilar material audiovisual e información relacionada coa música e o baile de tradición oral.

O afastamento do contexto académico sobresae na carencia de metodoloxía, a cal se caracteriza por unha mingua significativa ou directamente a inexistencia tanto da fase organizativa como da fase posterior dedicada á análise de resultados, quedando polo tanto reducido este traballo de campo á fase central de visita ao propio campo e a súa respectiva recompilación de datos.

\subsection{Antecedentes}

Podemos considerar como antecedentes das recollidas os procesos de compilación de música tradicional que deron lugar á publicación de diferentes cancioneiros que aparecen no territorio galego dende finais do s. XIX, nun primeiro momento moi vinculados á corrente folklorista de voga en toda Europa.

O primeiro destes cancioneiros é o Cancionero Popular Gallego: y en particular de la provincia de La Coruña de Pérez Ballesteros (1885-1886), no cal só aparecen os textos utilizados para a interpretacións de cancións, e ao que lle segue en relevancia e data o Cantigueiro popular de Marcial Valladares de 1887, aínda que foi publicado en 1970.

A partir deste momento acrecéntase o interese sobre a música de tradición oral e aparecen diferentes traballos que Groba (1998) trata de distribuír en dúas grandes tendencias, poética e científica, que se distinguen no tratamento do material compilado, no primeiro caso máis dedicado á reinterpretación e no segundo máis próximo á teorización e publicación de cancioneiros.

Ao redor da tendencia poética destacan a figura de Perfecto Feijóo e a Sociedade de Folklore Gallego comandada por Emilia Pardo Bazán (Clémessy, 2004), e entre as publicacións afíns podemos falar de Cantares viejos y nuevos de Galicia de Marcial de Adalid (1887), Canto y bailes populares de Galicia de José Inzenga (1888) ou Así canta Galicia de Daniel González (1963).

Por outra banda, en relación á tendencia científica destaca Casto Sampedro, caracterizado pola organización dunha rede de investigadores e investigadoras que achegaban melodías de diferentes puntos da xeografía galega (Groba, 1998), e que deron lugar ao Cancioneiro musical de Galicia en 1910 (editado en 1942). A partir dos 30 aparecen publicacións vinculadas co Seminario de Estudos Galegos, entre elas Terra de Melide (1993) e Cancioneiro galego (1973), ambos de Martínez Torner e Bal y Gay.

Atendendo ao parón cultural que supuxo a Guerra Civil e a sucesiva ditadura, a seguinte gran publicación é o Cancioneiro Popular Galego de Schubarth e Santamarina (1984-85), unha renovación científico-musical que trouxo consigo as consideracións musicolóxicas de voga en Europa e que deu como resultado outras publicacións máis breves: Escolma (unha redución do cancioneiro do 1991), Cancioneiro galego de tradición oral (1982) e Cantigas populares (1983).

Tamén poderiamos falar dunha serie de compilacións fonográficas no territorio galego, entre os que destacarían o traballo de Alan Lomax en 1952, as gravacións de García Matos tamén durante os 50 e Recolleita (1981) de Pablo Quintana (Estévez, 2008). 
Dende unha perspectiva diferente, tamén consideramos necesaria facer referencia á influencia da Sección Feminina no proceso das recollidas e na situación en xeral da música e baile tradicional galego. Durante a ditadura, a Sección Feminina erixiuse como un elemento de control para o franquismo, utilizando para isto a tradición relacionada coa música e o baile a través da súa uniformización, principalmente (Campos, 2008). Herdeira do folklorismo, modificou a tradición ao seu antollo e tamén foi o momento no que esta se converteu nun ente estático con oco no contexto urbano, é dicir, desnaturalizándoa e comezando a estela da ensinanza da música e baile de tradición oral a través de clases.

É relevante o papel da Sección Feminina neste eido xa que, a meirande parte das primeiras e primeiros compiladores participes das recollidas foron integrantes de Asociacións Folclóricas e Culturais herdeiras dos grupos artellados durante o franquismo (Campo, 2008).

Eu cando empezaba en baile había os grupos de Sección Femenina, que eles buscaban un espectáculo para mostrar, non era algo que seguira vivo dentro do pobo, buscaban máis o espectáculo (González, 2021).

En definitiva, consideramos necesario facer referencia a estes antecedentes a pesares de que a súa influencia no proceso de recollidas foi desigual, nun primeiro momento a proximidade co traballo da Sección Feminina estivo moito máis presente que os cancioneiros e publicacións, os cales foron descoñecidos por moitas e moitos dos compiladores ata ter xa un longo percorrido na realización de traballo de campo.

Neste sentido, é curioso ver como estudos practicamente coetáneos como os de Schubarth, non tiveron influencia ou relación coas recollidas, senón que o seu vínculo se produciu moito máis tarde.

Que o traballo de Dorothé Schubarth xa estaba ahí cando nos empezamos a ir de recollidas, e nos, por exemplo, non sabíamos nin sequera que existía Dorothé Schubarth (Segade, 2021).

\section{METODOLOXÍA}

\subsection{Obxectivos}

O obxectivo principal deste artigo é o de investigar, describir e delimitar o proceso das recollidas de música e baile de tradición oral en Galicia, establecendo un claro énfase nos seus comezos e momentos álxidos, enmarcados durante os anos 90.

Como obxectivos secundarios:

- Aportar referencias bibliográficas sobre as recollidas, ata o momento practicamente inexistentes.

- Incluír no contexto académico as experiencias de profesionais da música e baile tradicional. 


\subsection{MÉTODO}

A realización deste artigo descríbese como un estudo de caso no que se combinan dous elementos con participación desigual. Un primeiro apartado correspondería coa busca bibliográfica a cal, no eido da música e baile tradicional en Galicia, non é abundante e motivo polo que se fai necesaria a introdución doutros métodos para a achega de información. Este segundo gran bloque correspóndese coa realización de entrevistas, sobre as cales detallamos a continuación os diferentes apartados executados.

\subsubsection{PARTICIPANTES}

As persoas escollidas para participar das entrevistas correspóndense cun perfil profesional moi concreto: profesionais da música e baile tradicional que tiveran realizado labores de traballo de campo durante a década dos 90 e que, polo tanto, participaran activamente do fenómeno das recollidas en Galicia.

Tratouse de seleccionar persoas de diferentes puntos xeográficos e que non compartiran grupos de traballo durante as recollidas, para así poder achegarnos a este fenómeno dende diferentes perspectivas e vivencias.

Convimos con todas elas a participación neste estudo a través da firma dun documento de información, compromiso de confidencialidade e consentimento informado.

A relación de entrevistados e entrevistadas é a que segue:

- "Xisco" Feijóo: Cantante, bailador, coreógrafo, mestre da escola ETRAD e coordinador da sección de canto da OFG SonDeSeu. Ten realizado labores de recuperación etnográfica durante máis de trinta anos e múltiples colaboracións en discos e espectáculos, ademais de estar a presentar actualmente o seu propio proxecto: Peixe.

- Felisa Segade: docente e intérprete de música tradicional galega de formación autodidacta que comeza no 86 a realizar recollidas como xeito de nutrir os seus traballos musicais. Posúe unha ampla experiencia docente e discográfica, podendo sinalar a participación nos grupos Brincadeira e Leilía, entre outros.

- Fransy González: os seus inicios e principal foco de actividade como mestra vincúlanse a A.C. Xiradela de Arteixo, coa que ademais leva a cabo un extenso traballo de investigación na comarca de Bergantiños. Ten realizado colaboracións con diversos grupos, enmarcándose hoxe en día nun proxecto musical xunto a Davide Salvado e Cibrán Seixo.

- María Vidal: Directora e mestra de diversos grupos de canto e pandeireta en diferentes escolas e asociacións, ademais de integrante de diversos grupos de música tradicional e folk. Tamén ten colaborado en diferentes traballos discográficos, estando actualmente inmersa no proxecto Cantigas de Elena. 


\subsubsection{INSTRUMENTO}

O instrumento base empregado foi a entrevista semiestruturada, na que se expoñen uns bloques temáticos previos á conversa e dende os cales poder adaptarse aos intereses, vivencias ou características da propia ou propio entrevistado (Corbetta, 2010).

Para a transcrición respectouse o criterio de literalidade estilística, ademais de proceder a unha validación dos datos obtidos a través dunha revisión da transcrición por parte dos e das informantes. Nas referencias bibliográficas sinalamos estas entrevistas baixo o título: comunicación persoal.

\subsubsection{PROCEDEMENTOS}

O desenvolvemento do estudo parte dun deseño circular aberto que nos permita revisar e reflexionar constantemente sobre o proceso de investigación e os datos obtidos (Flick, 2004). Isto supón que a través da propia recompilación de datos se vaian reconstruíndo continuamente os supostos teóricos sobre os mesmos.

Por outra banda, para asegurarnos dun proceso ético e fidedigno dos datos, tomamos como referencia a fiabilidade dos mesmos cunha recompilación clara tanto no proceso de obtención como no de codificación, a validez destes a través da revisión por parte dos e das informantes das transcricións, e a triangulación de datos obtida grazas á participación de diversos entrevistados e entrevistadas.

\section{ANÁLISE DE RESULTADOS}

\subsection{AS RECOLLIDAS}

Como xa sinalamos no apartado do marco teórico, recollidas é o nome co que se popularizou dende os 80 e, especialmente, na década dos 90 a unha serie de visitas a zonas rurais co obxectivo de coñecer aspectos relacionados coa cultura tradicional, especialmente a música e o baile (Vidal, 2021).

Recordemos tamén que este proceso non tivo relación nin na súa orixe nin no desenvolvemento co campo académico-científico, aspecto que puido potenciar a conexión emocional das e dos compiladores co propio proceso. Mostra disto recollemos as palabras de "Xisco" Feijóo (2021), quen ao preguntarlle por unha definición para o termo recollidas nos comunicou: "O que significou para min, nun inicio, foi directamente unha paixón".

\subsubsection{OBXECTIVOS}

Poderiamos sinalar dous grandes obxectivos que motivaron a realización de recollidas: Por unha banda a compilación de urxencia, entendendo que as músicas e bailes de tradición oral estaban a piques de desaparecer ao teren cambiando os contextos orixinais onde se producían. As recollidas enfocábanse a persoas de avanzada idade, xa 
que se buscaba unha información afastada da realidade do momento, retomando as épocas nos que os e as informantes eran mozas; polo tanto estas experiencias, de non recollérense, desaparecerían co falecemento destes individuos. "Xisco" Feijóo (2021) fai referencia a esta idea cando nos conta:

Había unha frase entre nos, que nos mirabamos, e emocionados, con bágoas nos ollos, decíamos: Díos mío, esto morre! Estamos vivindo os últimos estertores, porque vimos un sábado a noite a sabe dios donde, atopar algo [...] que [...] onde vivimos nos non existe en ningunha esquina[...]. Non o víamos nunca.

Do mesmo modo, Felisa Segade (2021) reflexiona sobre a revisión das recollidas na actualidade:

Eso xa non é recuperable, porque non hai a quen preguntar esto que perdiche. Porque igual nesa recollida hai unha muller de 80 anos e outra muller de 50, moi ben, a de 50 igual está viva pero non viviu a metade do que viviu a que tiña 80 , cando hai 30 anos. Entón, estamos falando de persoas que farían agora 100 e pico anos... esa información perdeuse e é unha das cousas que creo que vemos todos os que vamos de recollidas, ou fumos.

Ademais, esa compilación de urxencia veu tamén motivada polo propio descoñecemento de compiladores e compiladoras, ás que as visitas ás zonas rurais mostraron unha realidade completamente diferente:

Chegou un momento, polo menos na miña xeración, cando empezamos nos 80 , que foi tamén curiosidade porque a maioría viñamos doutras agrupacións, ou asociacións, que tiñan un xeito diferente de entender a música. [...] Empezamos a ver que había outra cousa, que había outro nivel. E entón petounos a curiosidade e empezamos a buscar, primeiramente arredor do máis próximo que tiñamos, e pouco a pouco fomos ampliando espazo (Vidal, 2021).

A outra gran motivación foi o aprovisionamento de material co que impartir aulas de música e baile tradicionais, as cales estaban a adquirir certa notoriedade pero para as cales non existía material previamente definido máis que aquelas ensinanzas deturpadas da Sección Feminina. Tanto Felisa Segade como Fransy González explican como as necesidades das Asociacións Culturais onde comezaban a ter contacto coa música e baile tradicionais propiciaron as saídas de campo:

En Cantigas empezarase a facer unha escola, [...]entoces eso tamén che fai que tu teñas [...] que ter material... que enseñas? $O$ noso director non sabía tocala pandeireta... enton ti vías ahí esa cantidade de material... e decidimos que nos gustaría salir de recollida (Segade, 2021).

$\mathrm{Si}$, empezouse... e case se continúa, porque facía falta para a asociación, entonces formouse este grupo de investigación [...] Xirdela fundouse no 82 e a partir do 8485 empezouse a recoller... como había grupo de baile fíxose un grupo de investigación para que esas persoas puideran bailar, montar bailes... íbamos ás aldeas a facer ese traballo de campo ou de recollieta de cancións, bailes... (González, 2021).

Igualmente, "Xisco" Feijóo (2021) confirma este obxectivo, que el pon en segundo lugar e cualifica con certa negatividade ao comparala coa paixón inicial que mencionamos anteriormente: 
Esta paixón derivouse perniciosamente, un pouco, porque enseguida empezamos a ter un colectivo, $[\ldots]$ "O Fiadeiro" [...] queríamos poñer en práctica, o amago de facer un grupo novo de recuperación e, digamos, de representación o máis real posible do que atopabamos. Entón [...] aquela paixón foi un pouquiño invadida pola parte de búsqueda de repertorio novo, porque aquelo era todo inédito.

En resumo, podemos aglutinar as motivacións das recollidas coas palabras de María Vidal (2021):

Mesturábanse esas dúas cousas, por un lado a curiosidade de algo que nos parecía interesante e novo e, por outro lado, a necesidade de ter un repertorio para o teu grupo.

\subsubsection{DESCRICIÓN DO PROCESO}

Podemos datar na década dos 80 as primeiras recollidas en Galicia, aínda que hai referencias previas durante os 70, e, sen dúbida, o momento de máxima expansión deste fenómeno foi durante os 90 . A conformación dos grupos de traballo para a realización de recollidas enmarcábase dentro de lazos de amizade, tendo polo tanto un forte carácter de ocio e socialización:

Dentro do equipo de traballo que era, que non lle chamabamos equipo de traballo, para nos era ocio, $[\ldots]$ pois para nos a nosa paixón era eso, porque tamén tiñamos unha parte de convivencia marabillosa. Estabamos cos vellos, traballamos e tal, pero logo tiñamos unha casa rural para pasar a fin de semana e, bueno, desfrutar, ir a praia, ir ás discotecas a Carballo ou en calquera outro sitio, non? Iso non faltaba pero sempre había a motivación de primeiro ir a buscar esto (Feijóo, 2021).

Os grupos de traballo estaban case sempre formados por persoas moi novas vinculadas a algunha asociación de carácter folclórico ou cultural que se desprazaban, dentro das súas posibilidades, por diferentes zonas de rural galego:

Entón, o mundo das recollidas para os que fomos nalgún momento empezou sendo como un hobbie, como algo que... bueno, porque entramos nunha asociación cultural donde bailabas e onde podes descubrir que as nosas xentes cantaban e bailaban, e onde vas vendo que non só e unha forma de divertirse senón que é algo cultural, moitísimo máis grande do que tu podes empezar a ver (Segade, 2021).

Era en plan amigos, claro, e que o facías en plan divertimento tamén. Si, para recoller pero eramos mozos, entonces con esos anos pois decíamos: hoxe vamos de excursión a non sei donde a ver se encontramos algo (González, 2021).

As melloras técnicas e metodolóxicas avanzaron de xeito pausado, vinculado tanto ás características anteriormente mencionadas como á falta de financiación externa:

Primeiro [...] vas a xunto ela [a informante] e o principio cun papel... coche, papel e boli, nada mais, non tiñamos nada mais.

Despois, como víamos que non dabas apuntado, pois unha gravadora, que con eso estuvemos anos e anos. [...] cunha gravadora e nada máis. E o seguinte paso? Pois cámara de vídeo, evidentemente. Nos anos 90 houbo unha recollida na Silva que foi espectacular, non sei, igual había 100 persoas bailando, todo o pobo, e eu decía: que pena de tres cámaras, porque con unha non facías nada, claro! (González, 2021). 
Pero non eramos técnicos, [...] non eramos fotógrafos nin tiñamos carreira de etnomusicoloxía nin nada, entón dedicábamonos ao que nos pedía o corazón [...] En todo o que era o fenómeno das recollidas, nos daquela nos sentíamos moi abandonados, porque ninguén nas institucións lle daba valor a eso (Feijóo, 2021).

Todo isto danos conta duns inicios dificultosos debido á inexperiencia e descoñecemento tanto do propio obxecto de estudo, das músicas e bailes de tradición oral, como do proceso de investigación. Aínda así, a perseveranza das persoas implicadas no proceso converteron o fenómeno das recollidas nun gran impulsor para a música e baile tradicional, ademais de ir mellorando paseniñamente os diferentes elementos presentes nas recollidas, dende o apartado metodolóxico, por exemplo na visita a un mesmo lugar en reiteradas ocasións (Feijóo, 2021) ou a comparación de datos de diferentes lugares (Segade, 2021) ata o tecnolóxico, co aprovisionamento de elementos para a gravación e a aprendizaxe no seu uso.

E pouco a pouco sí que nos fumos.... Fumos aprendendo como facelas cousas, fumos aprendendo de moitos erros que tuvemos nun principio e que seguramente ahora seguimos tendo, ou outros erros diferentes, pero pouco a pouco fomos aprendendo e fumos ampliando un pouco o que é a recollida, non solamente a música, sinón contextualizalo todo, saber sobre esa persona, sobre a súa familia... porque todo eso axudate a contextualizar, que para nos ahora é o importante, ademais da música e dos bailes e do que che podan contar sobre vestuario, etc. pois tamén saber que pasaba, porque se facía eso, sinón parece que queda todo un pouco en música e nada máis, e non é (Vidal, 2021).

Como dicíamos, durante os 90 deuse o gran momento de expansión das recollidas, a partir do cal estas foron diminuíndo especialmente polo paso do tempo, o falecemento de informantes e a perda dos últimos elos da transmisión oral, o cal provocou que a propia información recollida no traballo de campo presentase fondas diferenzas:

Os que tuvemos a sorte de ver eses grupos grandes de xente bailando, tocando... si podemos ao millor, con unha ou dúas personas, facernos unha idea do que era, pero alguén que nunca estuvo e chega de novo a eso, eu creo que lle ten que resultar difícil. Incluso o xeito de estar de esa persona é diferente, está contigo, está informando, sendo muy xenerosa, muy amable... pero ti non estás vendo as risas coa compañeira, e o meterse co outro... que dis: Ah! Era esto! Entón perdes muitas cousas. Si que houbo unha perda grande de estes anos a ahora, pero eu penso que é inevitable (Vidal, 2021).

\subsubsection{RESULTADOS}

O principal resultado das innumerables recollidas que se realizaron no territorio galego por entidades e individuos diferentes, foi a conformación de arquivos privados formados por unha inxente cantidade de material audiovisual sen catalogar ou analizar (García, 1998; Feijóo, 2021).

Despois depende de xente, hai xente que ten os arquivos esquecidos, esas cintas que ao mellor xa non valen para nada, despois hai xente que preocupouse de dixitalizalo todo, nos pasamos moitísimos tempo dixitalizando tanto vídeo como audios, porque somos conscientes de que eso á material e vaise perder, entón tratalo do mellor xeito posible. Despois hai xente que non quere compartir eses arquivos que ten, os ten 
podridos, perdidos na casa e non quere compartilos con ninguén, non entendo porque pero é así, dáse así... Despois hai outra xente, eu falo por min, que temos a disposición do que queira todo o que temos, de feito hai dous anos a CentralFolque publicou un libro sobre Antón Fraguas e o 90\% das gravación que hai alí son nosas, porque pensamos que: a ver, que fan na casa? O obxectivo non é recopilar para mostrar, para recuperar e para que esto continúe adiante? Pois tes que cedelo se cho piden! (Vidal, 2021).

Este uso e difusión limitada do material obtido nas recollidas é a característica da que máis opinións podemos atopar nas escasas publicacións que mencionan esta realidade. García (1998: 228) fala do "uso restrinxido dos materiais recollidos nos traballos de campo", mentres que Dopico (2007: 111) sinala a inexistencia de análise ou catalogación ao definir uns "resultados [...] desiguais e ás veces imposibles de avaliar".

Sen embargo, tamén temos que ter en conta que o relevante número de persoas vinculadas ás recollidas foi un dos feitos máis importantes para a difusión e popularización da música e baile tradicionais a partires dos 90. Esta popularidade cristalizou na creación de numerosas asociacións e escolas onde se comezaron a impartir aulas de música e baile tradicional, e que serviron como motor para a concepción dun novo sector profesional a nivel de ensinanza e espectáculos (Felisa, 2021).

Sinón chega a ser por ese traballo copilatorio noso de tantos anos, hoxe probablemente non habería moitas cousas das que hai: nin as asociacións terían material para traballar, nin habería publicacións [...] E penso que tuvemos un papel especialmente relevante $[\ldots]$ eu penso que fixemos nos máis pola recopilación que os científicos (Vidal, 2021).

Deste xeito, todas aquelas persoas implicadas nas recollidas foron conformándose como especialistas a través da experiencia e coñecementos implicados na realización destas investigacións e a conseguinte transmisión dos mesmos, e sendo deste modo o primeiro elo na conformación do sector da música e baile tradicional en Galicia.

\subsection{INFLUENCIA DAS RECOLLIDAS NO EVENTO MUSICAL E NO BAILE}

$\mathrm{Na}$ realización das recollidas, as compiladoras e compiladores adoitaban interpelar aos recordos das e dos informantes sobre as músicas e bailes das que desfrutaban cando eran mozos, facendo para isto unha especie de recreación que consistía en facer unha festa ou reunión de consideracións semellantes. Pero entendendo que o feito musical non é un ente estático e que, do mesmo xeito, é resultado dunhas interaccións sociais cun obxectivos concretos, neste caso o goce e socialización, é indiscutible que a interpretación durante as recollidas propuxeron uns novos contextos que implicaron influencias nas propias músicas e bailes.

Primeiramente, a interacción entre compiladoras e informantes trae consigo unha relación social das que, moitas delas, acabaron con profundas relacións de amizade.

Porque unha persona cando ten confianza en ti, se convirte na túa amiga e se sinte relaxada, de verdá si dá o que de verdá que ten dentro. E creo que nós temos gravacións marabillosas en ese sentido, por exemplo en casa de Rosa e Aida Garrido 
Casqueiro de Moscoso... E que eu teño 12 anos de gravación, son doce anos da miña vida de ir á súa casa, de quedarme alí a durmir, de ir facelo pan de millo, de gravalas mentras cosían para algunha macro empresa puños de camisa, e mentras estaban cosendo, cantándome cousas... Non sei, creo que son gravacións absolutamente especiais, porque eran momentos especiais con persoas especiais (Feijóo, 2021).

Chegamos aos sitios e facemos amistade coa xente, hai xente que imos a visitar aínda ahora para tomar un café con eles, unha merenda, preguntarlles como están... moitos morren e vamos aos enterros. Chegas a ter unha relación personal con eles, entón xa ves que o das recollidas de forma aséptica, eu non a entendo así, entendo como o chegar a un lugar, entablar unha relación coa xente do pobo e preguntarlles polas cousas de antes: que era o que facían para divertirse... e enredado nesas cousas de que facían para divertirse, van outras cousas que che contan e que son súper interesantes, e dan unha serie de informacións súper valiosas, que ao millor non ten que ver coa música pero para contextualizala é súper importante, hai que escoitalo todo (Vidal, 2021).

Por outra banda, unha das características da música de tradición oral é a permanente variación e a adaptación de estímulos e influencias musicais ao propio repertorio, como por exemplo é habitual atopar melodías popularizadas a través de medios de comunicación como a radio adaptadas para cantar acompañadas de percusión de man ou para gaita. Deste modo, as recollidas tamén aportaron novas influencias, fundamentalmente a través de dous aspectos: a propia relación coa música e baile que as e os compiladores tocaban e a interacción entre informantes de diferentes puntos xeográficos.

Houbo un momento en que con todo este movemento de tanta xente recollendo e comezaron a facerse festas de xuntanza, quero decir, o que lle chamaban aquí os seráns ou foliadas noutros lados. Entón, o millor nun sitio como Imende [...] viñan as mulleres de Zas, as de Coristanco, as de Silván, como nos conocían...e elas contrataban un autobús, organizado polas mulleres, e ían a aquela cena, botaban ata as catro da mañá alí no patio do bar de Imende, en Carballo, bailando e unhas cantaban e tal. Evidentemente xordas e coxas non eran, estaban vivas, entón ves que hai outra xente que veu despois e a xente de Imende lle recolleu melodías que elas non cantaban orixinalmente, que llas sentiran naquelas noites que estabamos xuntos ás de Silván (Feijóo, 2021)

Entón empezou ahí a un proceso como de contaminación, e que levou a eso o aparecer esta xente na tele, e os mesmos recopilador ao mellor tamén eh? Pode ser que tamén, que muitas veces no afán de que elas tocaran ou que bailaran, e para que descansaran, ías ti e lle tocabas o que sabías, e resulta que de alí non sabías nada, pero sabías doutro sitio, e resulta que lles gustaba aquelo e entón querían aprender a facelo (Vidal, 2021).

Pola radio, pola televisión... cando empezou o Luar, que empezaron todos os vellos a ir ao Luar. Entón imaxínate un vello de Imende que esta vendo que está un vello de Cerqueda bailando e dixo: ai, ese punto eu non o sabía. E logo vai a tele, tócalle ir a el, e fai ese punto: si, si este punto é de Imende de toda a vida. E no, o millor foi o que viu na tele. Osea hai influencia? Si (González, 2021).

No propio momento das recollidas, aínda que aparecía un novo contexto é certo que existe un forte paralelismo, ao realizarse festas á semellanza do que ocorría no pasado. Pero a popularidade e interese que espertou a tradición nesta época trouxo consigo novos escenarios para a música e o baile e os e as súas protagonistas principais. 
Sen dúbida, o escenario máis representativo do que estamos a falar é o do xa mencionado programa da CRTVG Luar, ao cal se convidaban a asistir a veciñas e veciños das aldeas para tocar e bailar as músicas de tradición oral propias da súa zona, moitas veces animadas e animados polas compiladoras que se dedicaban a facer recollidas, como Mercedes Peón ou "Xisco" Feijóo. O que supuxo este feito foi, principalmente, un cambio na función da música e baile, os cales pasaron de servir como goce propio a converterse nun espectáculo, xa que se trataba de facer unha actuación para un público.

Por outra parte, tamén en ocasións se producían cambios na propia música, tal e como reflicte Maruja Grande Sobral (Maruxa das Cortellas, afamada tocadora de pandeiro) na entrevista que recolle Feixóo (2017), onde conta como cantos colectivos se subiron ao escenario de xeito solista:

Ao Chisco [Javier Feijóo «Xisco»], como nos lle chamamos, metéuselle nos cornos que había d'ir ao Luar-e eu sola. E eu díxenlle «eu non che vou sola», porque un solo hai que alentar, porque eu non podo cantar sen alentar-e, é como pasa aquí, sen unha voz que axude. E ao final fun. Eu tiña uns nervios, uns nervios que mimá. El díxome «estamos alí contigo». Ah! Pero eu dixen: "non, non, ou tendes que tocar ou bajar", ai tiña que facelo eu sola $[\ldots]$ pero tiña uns nervios... (75).

Ademais, o interese crecente tanto de compiladores como de medios de comunicación, trouxo consigo un novo auto-concepto para as e os informantes, dando valor a algo que moitas e moitos deles tiñan case no esquecemento e que, ademais, formaba parte da que fora a súa vida cotiá durante a súa xuventude.

Que me vas contar... de chegar os sitio, sacar as cámaras: esto é para o Luar? -Non. - E nos ides levar ao Luar? - Pois non, se queren podemos intentalo, pero non é con esa finalidade.

$\mathrm{Si}$, a partir dese momento si, e eso foi bo por un lado, porque a xente estaba máis disposta (Vidal, 2021).

Especialmente notable foi o emporderamento do xénero feminino a través da pandeireta como instrumento emblema. $\mathrm{O}$ que antigamente fora considerado como un elemento máis da vida cotiá sen ningún tipo de prestixio, pasaba agora a centrar o interese das e dos compiladores, preocupándose por un repertorio que quedara escondido tras o doutros instrumentos cunha categoría profesional, especialmente a gaita, cunha ligazón practicamente exclusiva ao xénero masculino (López Fernández, 2021).

Nas recollidas o habitual é que sexan case todo mulleres, que son as que se prestan, son as grandes transmisoras e as grandes informantes. Porque eles ou iban a partida, ou veñen un rato pero marchan porque: bah! Eso é cousa de mulleres, xa eles che din que son cousas de mulleres (Vidal, 2021).

\section{CONCLUSIÓNS}

En conclusión, atopámonos cun fenómeno de vital relevancia para o estado actual da música e o baile tradicional en Galicia, pero que conta con escasas referencias dende o campo académico, tanto polo seu nulo vínculo no proceso de investigación como no 
estudo posterior do evento. Ante esta panorámica apoiámonos firmemente nas palabras de Feijóo (2016) para valorar esta situación:

Por otro lado también resulta fundamental contar con aquellos compiladores y divulgadores del patrimonio inmaterial externos al mundo académico. Ademas de contener en sus archivos personales miles de horas de grabaciones con material musical muy valioso e inédito, estos agentes fueron articulando a lo largo de sus carreras una serie de discursos críticos sobre el objeto de estudio, fruto de un pensamiento reflexivo y razonado. Su conocimiento profundo de la tradición y de las claves simbólicas y performativas que encierra el patrimonio inmaterial de Galicia fue sistemáticamente invisibilizado en los estudios etnomusicológicos producidos desde la Academia (332).

Sen embargo, unha chamada de atención na que concordan todas as nosas entrevistadas é na imperiosa necesidade da integración das institucións públicas no coidado deste patrimonio inmaterial, do cal se veñen desentendendo dende o inicio do proceso das recollidas ata o día de hoxe.

Eu creo que é importante que houbera un fondo desas recollidas e desos documentos audiovisuais e gráficos para preservalos. Os arquivos tanto individuais como de asociacións [...] terían que estar nunha institución pública, é o de sempre, a administración non se preocupou nunca disto e a min preocúpame mogollón, supoño que a todo o mundo coma min que recolleu e que sigues recollendo, e é preocupante que o teñan que facer persoas individuais ou asociacións por amor á cultura, porque ao final corresponde á administración, o patrimonio é do pobo, entón tería que ser a administración quen o fixera (González, 2021).

Pero necesitamos tamén apoio das institucións, porque a nos, supoño que cho diría todo o mundo, a nos costounos moitísimos traballo, os cartos que puxemos ahí nin podes imaxinar, en ir dun lado a outro, quedar a durmir en sitios, os que tiñamos fillos moitas veces os fillos viñan con nos [...]É un traballo que por parte das institucións non está valorado suficientemente, penso que non saben moi ben o que é o patrimonio inmaterial, necesitamos xente nas institucións que defendan o patrimonio inmaterial. Máis aló do que somos as asociacións, é dicir, necesitamos políticos que tamén se preocupen do patrimonio inmaterial (Vidal, 2021).

Ademais, no campo da música e baile tradicional ése consciente da relevancia deste traballo pero tamén do nesgo do proceso:

É un pouco para poñerte... donde está a xente que empezamos e donde estamos... entonces, bueno, empezamos dunha maneira pobre, por así decilo, que dalgunha maneira fomos medrando e creo que medrando para ben, porque grazas a esos pobres hoxe en día tu estasme facendo esta entrevista. E creo que eso é muy bo. Que é unha pena por non empezar antes... porque por non chegar a este punto antes... pero que... bueno, que a ese nivel creo que non é tarde porque está esa recompilación, as gravacións están ahí, anque non se poidan estudiar todo o enriquecedoramente que puidera ser no seu momento e... si que se poden estudiar, hai moitas cousas gravadas, hai moitas cousas que se poden sacar, e conclusións que se poden sacar (Segade, 2021).

Sen embargo, como nos adiantaba Segade, compartimos tamén o gran abano de posibilidades que aínda nos ofrecen hoxe en día todos os materiais recompilados nas recollidas e que, con sorte, irán conformando publicacións e traballos da man de compiladores e compiladoras e novos e novas profesionais do sector: 
Creo que estamos no tempo de que toda esa cousa que vos non podedes vivir porque esa xente falta, esa xente morreu... pois que salga á luz, pero que salga á luz con estudios serios, moi serios. E que sexan serios en todo: serios na técnica, serios no teórico e serios na vivenza, e para eso eu ofrézome totalmente (Feijóo, 2021).

\section{REFERENCIAS BIBLIGRÁFICAS}

Adalid. M. (1887). Cantares viejos y nuevos de Galicia. Madrid: Pablo Martín.

Campos Calvo-Sotelo, J. (2008). La música popular gallega en los años de la transición politica (1975-1982): reificaciones expresivas del paradigma identitario (memoria para optar ao grao de doutor). Madrid: Universidad Complutense de Madrid. https://eprints.ucm.es/8801/.

Clémessy, N. (2004). Emilia Pardo Bazán y Perfecto Feijóo. Elogio y defensa del folklore $\begin{array}{llll}\text { musical gallego. } L a \quad \text { Tribuna, } & \text { 65-75. }\end{array}$ http://revistalatribuna.gal/index.php/TRIBUNA/article/viewFile/22/35.

Corbetta, P. (2010). Metodología y técnicas de investigación social. Madrid: McGraw Hill.

Dopico, P. (2007). O ensino da música tradicional: perspectivas de futuro. En I congreso de ensinantes de música tradicional galega-actas-, 105-113. Orzán: Asociación de Gaiteiros Galegos.

Estévez, X. (2008). As gravacións da música galega (1975-2000). 500 horas de música, 500 artistas e grupos. 10.000 temas. Lugo: Editorial TrisTram S.L.

Feijóo, J. (2016). Este pandeiro que toco. La entrevista etnográfica como herramienta para la reconstrucción del mapa histórico del repertorio acompañado de pandero cuadrado en Galicia. En III Encuentro Iberoamericano de Jóvenes Musicólogos: actas, 331-339. Tagus-Atlanticus Associação Cultural. https://research.unl.pt/ws/portalfiles/portal/2378596/b80448_78596170c0fc43e58 6b6faf494af9718.pdf .

Feixóo, X. (2017). Maruxa das Cortellas. Tocadora do pandeiro... Santiago de Compostela: aCentralFolque.

Feijóo, X. (2021). Comunicación persoal.

Flick, U. (2004). Introducción a la investigación cualitativa. Madrid: Ediciones Morata.

García, A.L. (1988). As fontes do folk. Os cancioneiros. A tradición oral. Recollidas actuais. En Galicia fai dous mil anos. O feito diferencial galego. Música, v. I., Grupo Milladoiro (coord.), 225-237. Santiago de Compostela: A Editorial da Historia; Museo do Pobo Galego.

González, D. (1963). Así canta Galicia. Ourense: La Región.

González, F. (2021). Comunicación persoal.

Groba, X. (1998). A recompilación da música tradicional en Galicia. En Galicia fai dous mil anos. O feito diferencial galego. Música, v. II., C. Villanueva (coord.), 351-402. Santiago de Compostela: A Editorial da Historia, Museo do Pobo Galego. 
Inzenga, J. (2005). Cantos e bailes de Galiza. Ourense: Difusora de letras, artes e ideas. (orixinal de 1888).

Latham, A. (coord.) (2009). Diccionario enciclopédico de la música. México D.F.: Fondo de cultura económica.

López Cobas, L. (2013). Historia da música en Galicia. Sarria: Ouvirmos.

López Fernández, C. (2021). Perspectiva de xénero na tradición galega: o rol feminino na música de tradición oral. En Actas del III Congreso de Música y Cultura para la Inclusión y la Innovación, R. Chao-Fernández, F.C. Rosa Napal, A. ChaoFernández, C. Guillanders, \& R.M. Vicente Álvarez (Eds.), 40-44. Universidade da Coruña. http://hdl.handle.net/2183/28162.

López Fernández, C. (En prensa). La música de tradición oral en Galicia: propuesta para su clasificación. En Gestión de la cultura: lo que hacemos los humanos, Vives López (dir.). Tirant editorial.

Manzano, M. (1995). La jota como género musical. Un estudio musicológico acerca del género más difundido en el repertorio tradicional español de la música popular. Madrid: Editorial Alpuerto, S.A.

Martí, J. (1998). A tradición vista a través do folklorismo”. En Galicia fai dous mil anos. O feito diferencial galego. Música v. II, C. Villanueva (coord.), 323-350. Santiago de Compostela: A Editorial da Historia; Museo do Pobo Galego.

Martí, J. (1999). La tradición evocada: folklore y folklorismo. En Tradición oral, Eloy Gómez Pellón et al. (eds.), 81-108. Oiartzun: Aula de Etnografía, Universidad de Cantabria.

Martínez Torner, E. e Bal y Gay, J. (1933). Folk-lore musical de Melide. En Terras de Melide, 539-566. Santiago de Compostela: Seminario de Estudos Galegos Editorial NÓS.

Martínez Torner, E. e Bal y Gay, J. (1973). Cancionero gallego. A Coruña: Fundación Pedro Barrié de la Maza.

Nettl, B. (1985). Música folklórica y tradicional de los continentes occidentales. Madrid: Alianza Editorial S.A.

Pérez Ballesteros, J. (1885-1886). Cancionero popular gallego: y en particular de la provincia de La Coruña. Madrid: Librería de Fernando Fe.

Quintana, P. (1981). Recolleita [CD]. Santiago de Compostela: Clave Records.

Randel, D. M. (ed.) (1997). Diccionario Harvard de música. Versión española de Luis Carlos Gago. Madrid: Alianza Editorial.

Sampedro, C. (2007). Cancionero musical de Galicia. A Coruña: Fundación Pedro Barrié de la Maza (orixinal de 1942).

Segade, F. (2021). Comunicación persoal.

Valladares, M. (1970). Cantigueiro Popular. A Coruña: Fundación da Real Academia Galega.

Vidal, M. (2021). Comunicación persoal. 